Original Research

\title{
A simplified approach to control cell adherence on biologically derived in vitro cell culture scaffolds by direct UV-mediated RGD linkage
}

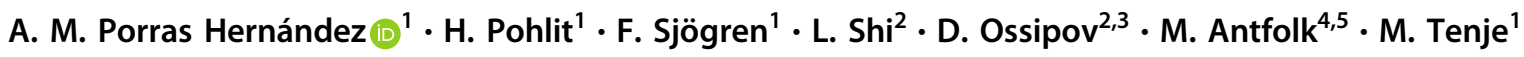

Received: 4 May 2020 / Accepted: 30 September 2020 / Published online: 14 October 2020

(c) The Author(s) 2020

\begin{abstract}
In this work, we present a method to fabricate a hyaluronic acid (HA) hydrogel with spatially controlled cell-adhesion properties based on photo-polymerisation cross-linking and functionalization. The approach utilises the same reaction pathway for both steps meaning that it is user-friendly and allows for adaptation at any stage during the fabrication process. Moreover, the process does not require any additional cross-linkers. The hydrogel is formed by UV-initiated radical addition reaction between acrylamide (Am) groups on the HA backbone. Cell adhesion is modulated by functionalising the adhesion peptide sequence arginine-glycine-aspartate onto the hydrogel surface via radical mediated thiol-ene reaction using the nonreacted Am groups. We show that $10 \times 10 \mu \mathrm{m}^{2}$ squares could be patterned with sharp features and a good resolution. The smallest area that could be patterned resulting in good cell adhesion was $25 \times 25 \mu^{2}$ squares, showing single-cell adhesion. Mouse brain endothelial cells adhered and remained in culture for up to 7 days on $100 \times 100 \mu \mathrm{m}^{2}$ square patterns. We see potential for this material combination for future use in novel organ-on-chip models and tissue engineering where the location of the cells is of importance and to further study endothelial cell biology.
\end{abstract}

\section{Graphical Abstract}
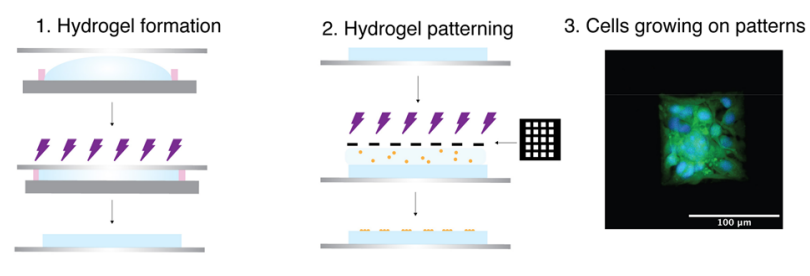

\section{Introduction}

M. Tenje

maria.tenje@angstrom.uu.se

1 Science for Life Laboratory, Department of Materials Science and Engineering, Uppsala University, Uppsala, Sweden

2 Department of Chemistry-Ångström, Uppsala University, Uppsala, Sweden

3 Department of Biosciences and Nutrition (BioNut), Karolinska Institutet, Huddinge, Sweden

4 BRIC-Biotech Research and Innovation Centre, Faculty of Health and Medical Sciences, University of Copenhagen, Copenhagen, Denmark

5 Novo Nordisk Foundation Center for Stem Cell Research, Faculty of Health and Medical Sciences, University of Copenhagen, Copenhagen, Denmark
Biomaterials are widely used in biological research and pharmaceutical development as biomimetic cell culture scaffolds to increase the in vivo resemblance of in vitro models [1]. For this purpose, hydrogels belong to a particularly attractive group of biomaterials due to their highwater content, which mimics the in vivo extracellular matrix (ECM) mechanical and physical properties. Furthermore, their high permeability for oxygen and nutrients [2] is important to support long-term cell cultures. In most situations, cell adhesion on the whole hydrogel scaffold is preferred, but for some applications, such as cell-cell interaction studies, one may wish to control the cell adhesion spatially. This can be achieved by preparing a nonadhesive hydrogel and patterning cell-adhesion motifs in the 
areas of interest. Previous reports have achieved this using synthetic hydrogels such as poly(ethylene glycol)-diacrylate where controlled cell adhesion was induced via the peptide sequence Arg-Gly-Asp (RGD) [3, 4]; poly(vinyl alcohol) using polydopamine to achieve cell adhesion [5] and on polyacrylamide using fibronectin and laminin to control the adhesion of the cells [6]. While synthetic and inert materials offer greater control over the biological responses and material properties, they do lack the inherent biological activity that naturally derived hydrogels hold $[2,7,8]$.

For studies of cell interactions in the neurovascular unit, hyaluronic acid (HA), a naturally derived polysaccharide, represents a particular interest as it constitutes an integral part of the brain ECM [9]. HA is a glycosaminoglycan and the high molecular weight HA does not promote cell adhesion, which lends itself as an ideal substrate for controlled cell-cell interaction studies. In previous work using HA, cell adhesion was achieved by linking RGD peptides to the HA molecule by Michael-type addition reactions prior to hydrogel formation [10-15]. However, these approaches do not allow for selective functionalization of adhesion peptides in spatially defined areas due to the ubiquitous presence of peptide throughout the complete 3D structure of the hydrogel. Attachment of adhesion peptides after the hydrogel formation would enable a greater control over the scaffold fabrication process. This is made possible using photo-induced radical addition reactions in combination with photomasks shielding some areas of the hydrogel and following this approach, radical thiol-ene reactions, one type of UV-initiated radical addition reactions, have been used [16-18]. Jing et al. [19] used this reaction to both form the hydrogel and attach the RGD peptide, but as the RGD peptide is attached to the HA chains before hydrogel formation, spatial control of the functionalised patterns could still not be obtained. In a previous publication, we immobilised RGD by radical thiol-ene addition in a 3D HAacrylamide (HA-am) hydrogel with spatial control using additive manufacturing but we did not investigate cell adhesion [16]. Gramlich et al. [17] used radical thiol-ene addition to form the gel and attach peptide from norbornylated HA and a di-thiol cross-linker. Later, the same group patterned RGD peptides using radical thiol-ene addition after forming electrospun HA scaffolds by Michael-type addition reaction [18]. Griffin et al. [20] used a more sophisticated two-step process that includes a UVmediated deprotection of the reaction site for RGD binding after hydrogel formation by Michael-type addition reaction [20]. Goubko et al. [21] formed the hydrogel and attached "caged" RGD peptides via amidation reactions where uncaging was spatially controlled using photolabile caging groups. All these methods do show controlled cell adhesion but they include either the necessity of a di-thiol crosslinker molecule, complex sample preparation processes (electrospinning) or multiple time-consuming steps to bind the RGD peptides (using protection groups, "caging").

In this work, we show a simplified approach using moulded culture scaffolds and a direct UV-mediated RGD linking approach. To make the process as user-friendly and flexible as possible, we have prepared an HA derivative (HA-am) where the acrylamide (Am) groups of the HA-am macromolecules serve both as the cross-linking and the functionalization groups via UV-induced radical addition reaction. This eliminates the need for the addition of crosslinker molecules like di-thiols, which might alter the material properties of the final hydrogel scaffold. Both cross-linking and peptide attachment are initiated by UV light exposure enabling fast reaction kinetics and spatiotemporal control [22]. In this work, we show that micrometre scale features of RGD could be patterned on the hydrogel, down to $10 \times 10 \mu \mathrm{m}^{2}$, and that these patterns result in spatial control of mouse brain microvascular endothelial cell adhesion.

\section{Materials and methods}

Sodium hyaluronate (100-150 kDa) was purchased from Lifecore Biomedical. Dialysis membranes Spectra/Por (MW cut off $3.5 \mathrm{kDa}$ ) were purchased from SpectrumLabs. Tetrahydrofuran dry, hydrochloric acid ( $\mathrm{HCl}) 37 \%$, Dulbelco's phosphate buffer saline (DPBS) and sodium chloride were purchased from Fischer Scientific. 3-(Trimethoxysilyl)propyl methacrylate, $N$-Boc-ethylenediamine, triethylamine anhydrous, acryloyl chloride, dioxane, $N$-(3-dimethylaminopropyl)$N^{\prime}$-ethylcarbodiimide hydrochloride, 1-hydroxybenzotriazole hydrate, acetonitrile anhydrous, sodium hydrogen carbonate and photo-initiator Irgacure 2959 were purchased from Sigma Aldrich. Calcein AM, propidium iodide, minimum essential medium (MEM) without phenol red, Dulbecco's modified Eagle medium (DMEM), high glucose Glutamax and fetal bovine serum (FBS) were purchased from Fisher Scientific. RGDSC, 5FAM-RGDSC, GCGYRGDSPG and 5FAMGCGYRGDSPG peptides were purchased from Innovagen AB. Glass coverslips and absolute ethanol were purchased from VWR. Plus One Repel-Silane ES was purchased from GE Healthcare Life Sciences.

\subsection{Synthesis of $\mathbf{N}$-(2-aminoethyl) acrylamide linker}

$N$-(2-aminoethyl) acrylamide linker was prepared by a three-step synthesis as described previously [23]. Briefly, $N$ Boc-ethylenediamine $(4.0 \mathrm{~g}, 25 \mathrm{mmol})$ was diluted in dry tetrahydrofuran. Triethylamine $(3.0 \mathrm{~g}, 30 \mathrm{mmol})$ was added to the solution and cooled down in an ice bath. In a separate flask, $2.44 \mathrm{~mL}$ (30 mmol) solution of acryloyl chloride in dry THF was prepared and added dropwise to the $N$-Boc- 
a<smiles></smiles><smiles>CC(C)(C)OC(=O)NCCNC(=O)/C=C/OC(=O)c1ccccc1</smiles><smiles>NCCNC(=O)C=CCl</smiles><smiles>CC(C)(C)Cl</smiles>

b
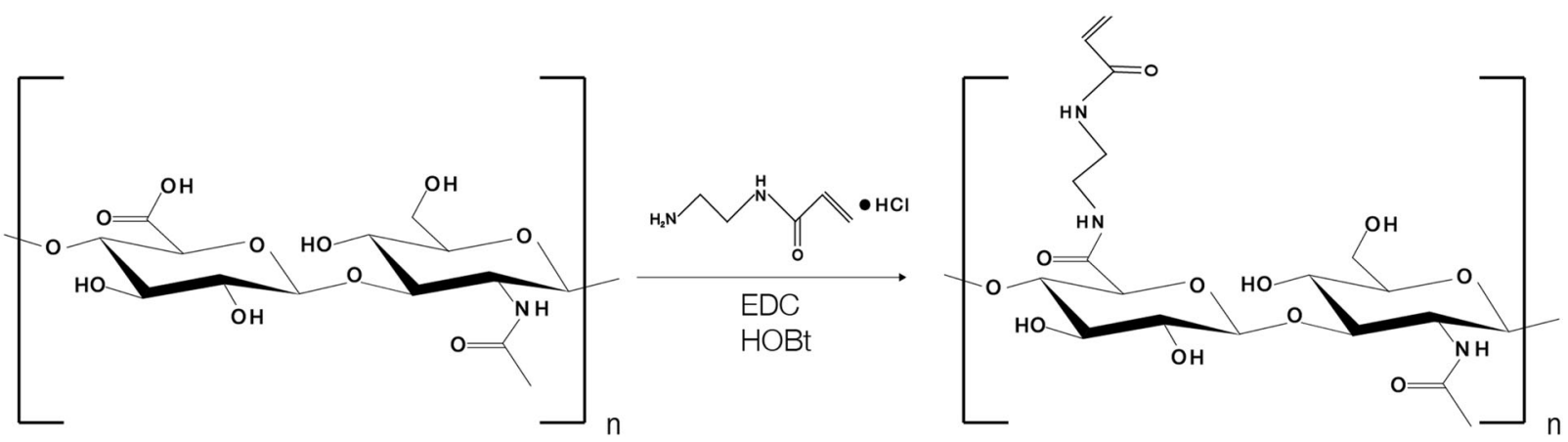

Fig. 1 A Synthesis of $\mathrm{N}$-(2-aminoethyl) acrylamide linker and B subsequent preparation of HA-am derivative by amidation of native HA with the linker

ethylenediamine $(4.0 \mathrm{~g}, 25 \mathrm{mmol})$ over $6 \mathrm{~min}$. The reaction mixture was left magnetically stirred on an ice bath for $2 \mathrm{~h}$ and afterwards at room temperature overnight. The mixture was then diluted with a solution of sodium hydrogen carbonate $\left(\mathrm{NaHCO}_{3}\right)$ and finally mixed with dichloromethane (DCM). The two-phase mixture was separated, the DCM phase was washed with $\mathrm{NaHCO}_{3}(100 \mathrm{~mL})$ and saturated brine $(100 \mathrm{~mL})$. The product, $N$-Boc-aminoethyl acrylamide (Boc-AEAA), was isolated by drying the DCM phase over sodium sulphate and finally evaporating the solvent on a rotary evaporator. The residue was dried in a vacuum chamber overnight. To remove the Boc protecting group, the Boc-AEAA was diluted with a solution containing concentrated $\mathrm{HCl}$ and dioxane (Fig. 1A). The mixture was stirred for $4 \mathrm{~h}$, protected from light and at room temperature and finally evaporated.

\subsection{Synthesis of hyaluronic acid-acrylamide derivative (HA-am)}

HA was functionalized with Am groups by reacting the carboxylic acid group of the HA backbone and the amino group of $N$-(2-aminoethyl) acrylamide linker (Fig. 1B) according to previous reports [24]. Sodium hyaluronate (200 mg, MW $=135 \mathrm{kDa}$ ) was dissolved in deionized water at a concentration of $8 \mathrm{mg} / \mathrm{mL}$. $N$-(2-aminoethyl) acrylamide linker $(56 \mathrm{mg})$ was added to the HA solution. HOBt $(72 \mathrm{mg})$ was separately dissolved in a $1: 1(\mathrm{v} / \mathrm{v})$ mixture acetonitrile $(1.4 \mathrm{~mL})$ and deionized $\mathrm{H}_{2} \mathrm{O}(1.4 \mathrm{~mL})$ at a concentration $27 \mathrm{mg} / \mathrm{mL}(3.0 \mathrm{~mL})$ by slight heating. Once the HOBt solution was cooled to room temperature, it was added to the HA solution. The $\mathrm{pH}$ of the reaction solution was adjusted to $\mathrm{pH} 6$ with $1 \mathrm{M} \mathrm{NaOH}$. The coupling reaction was initiated by the addition of EDC $(155 \mathrm{mg})$. The reaction was stirred at room temperature overnight in the dark. The reaction solution was then transferred to a dialyzing membrane and dialysed against $\mathrm{NaCl}$ solution $(0.1 \mathrm{M})$ adjusted to $\mathrm{pH} 3.5$ with $1 \mathrm{M} \mathrm{HCl}$ for $24 \mathrm{~h}$. Subsequently, the dialysis solvent was exchanged twice to distilled water adjusted to $\mathrm{pH} 3.5$ and twice to neutral distilled water. The solution was filtered to give rise to a clear and transparent solution. The filtered solution was freeze-dried to give a white paper-like material. The degree of modification with Am groups was calculated by ${ }^{1} \mathrm{H}$ NMR in $\mathrm{D}_{2} \mathrm{O}$, indicating that $14 \%$ of $\mathrm{HA}$ disaccharide repeating units were modified with Am groups.

\subsection{Fabrication of moulds for hydrogel formation}

Moulds for preparation of the hydrogel samples for the cell studies were fabricated using standard lithography techniques. Dry film photoresist (SUEX film) $200 \mu \mathrm{m}$ thick (DJ Microlaminates Inc) were laminated to $4^{\prime \prime}$ silicon wafer using a benchtop laminator. The SUEX film was exposed to UV light (30 s, eight cycles) using a mask aligner (KarlSüss M6) equipped with a $350 \mathrm{~W} \mathrm{Hg}$ lamp $(365 \mathrm{~nm})$. The film was exposed through a transparency photomask consisting of $200-\mu \mathrm{m}$-wide rings with a 7.8 -mm-inner diameter. After exposure, the SUEX film was baked at $85^{\circ} \mathrm{C}$ for $1 \mathrm{~h}$ and the pattern was developed for $40 \mathrm{~min}$ in developer mr-Dev500 (Micro Resist Technology $\mathrm{GmbH}$ ) and subsequently hard baked for $1 \mathrm{~h}$ at $200{ }^{\circ} \mathrm{C}$. There were in total 30 moulds that were diced for individual use with a dicing saw (Disco DAD 361). The final mould height $(\sim 220 \mu \mathrm{m})$ was determined using an optical profilometer (ZYGO). The moulds were treated with Repel-One-Silane (GE Healthcare) following the supplier's instructions to reduce the hydrogel adhesion to the moulds. 
For the rheology samples another mould was prepared comprising three layers of $500 \mu \mathrm{m}$ PDMS sheets bonded together. Before bonding, a rectangular opening $\left(24 \times 18 \mathrm{~mm}^{2}\right)$ was cut using a cutter plotter, used to mould the hydrogel samples.

\subsection{HA-am hydrogel sample preparation}

Irgacure 2959 photo-initiator was dissolved in DPBS at a concentration of $0.4 \%(\mathrm{w} / \mathrm{v})$ and HA-am was dissolved in the initiator solution at a concentration of $2 \%(\mathrm{w} / \mathrm{v}) .12 \mu \mathrm{L}$ of the solution was placed in the mould and covered by a methacrylate-functionalized cover glass, prepared following a previously published protocol [25]. The system was then irradiated with UV light to cross-link the HA-am derivative. Figure 2A, B shows a schematic of the fabrication process.

\subsection{Varying the UV light exposure dosage}

For the UV light exposure, a UV source (UV LED $356 \mathrm{~nm}$ Curing lamp, Tao Yuan Electron) with a constant power of

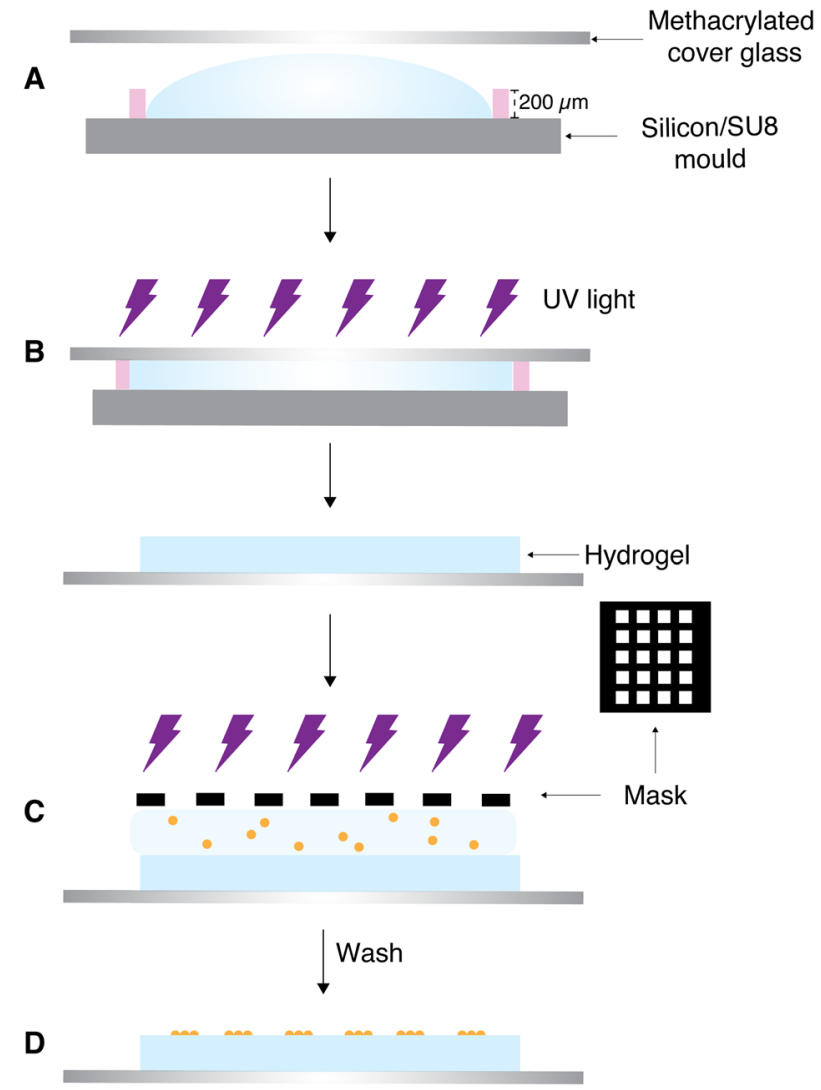

Fig. 2 Schematic of HA-am hydrogel formation and patterning with RGD peptides. A Hydrogel precursor solution (HA-am 2\% (w/v)) and photo-initiator (Irgacure $29590.4 \%$ in DPBS) was placed in the $\mathrm{Si}$ / SU8 mould and covered by a methacrylate-functionalized cover glass. B UV exposure. C RGD-peptide solution was pipetted on top of the gel, covered with a photomask and then exposed to UV light. D Unreacted peptides were removed by a washing step with DPBS
$100 \mathrm{~W}$, mounted onto a 3D-printed holder $10 \mathrm{~cm}$ in height was used. A calibration curve of the resulting UV intensity was provided by the manufacturer $\left(0.24 \mathrm{~W} / \mathrm{cm}^{2}\right.$ at $10 \mathrm{~cm}$ distance). For cross-linking and functionalization, the UV dose was varied by adjusting the exposure time at second intervals.

\subsection{Mechanical characterisation}

Hydrogel samples were prepared using one of the PDMS moulds $\left(24 \times 18 \times 1.5 \mathrm{~mm}^{3}\right)$ described above bonded onto a glass bottom. The hydrogel precursor was added in the mould and covered by another glass coverslip. The hydrogel precursor was exposed to varying UV doses $\left(1.4-8.2 \mathrm{~J} / \mathrm{cm}^{2}\right)$. Afterwards, the mould was disassembled and the hydrogel was left in supplemented cell media overnight. Three discs ( $8 \mathrm{~mm}$ diameter) were punched from the hydrogel and frequency sweep experiments were carried out on a Discovery HR-2 rheometer (TA Instruments) with a $8 \mathrm{~mm}$ Peltier steel parallel plate at $37^{\circ} \mathrm{C}$. A Poisons ratio of 0.5 was assumed [26] and the Young's modulus $(E)$ was calculated using the approximation $E=G^{\prime * 3}$, where $G^{\prime}$ is the shear modulus at a frequency of $1 \mathrm{~Hz}$. The value was chosen at $1 \mathrm{~Hz}$ as this is in the linear viscoelastic region.

\subsection{Patterning of HA-am hydrogel films with RGD peptides}

After hydrogel cross-linking, $10 \mu \mathrm{L}$ of a $0.5 \mathrm{mM}$ RGDpeptide solution was pipetted on top of the gel, covered with a photomask and then exposed to UV light. Subsequently, unreacted peptides were removed by a washing step with DPBS for $2 \mathrm{~h}$. Figure 2C, D shows a schematic of the fabrication process. The samples were left in supplemented media overnight inside an incubator $\left(37^{\circ} \mathrm{C}, 5 \% \mathrm{CO}_{2}\right)$. Different UV light intensities $\left(0.24-6.9 \mathrm{~J} / \mathrm{cm}^{2}\right)$ were evaluated to identify the minimum UV intensity required to ensure sufficient binding of RGD peptide and good pattern resolution.

Previously, when RGD-peptide sequences have been used to control cell adhesion, a longer sequence (GCGYGRGDSPG) has typically been used on HA-based biomaterials [10, 13-15, 17, 18, 27, 28], whereas a shorter peptide sequence (RDGSC) has typically been used on synthetic hydrogel materials [29-32]. In this study, we investigated cell adhesion using both the longer and the shorter sequences. For visualisation of the patterns, we used fluorescently labelled versions of both peptide sequences, leaving a total of four different peptides used in the study.

\subsection{Cell culture on HA-am-RGD hydrogels}

Mouse brain endothelial cells (bEnd.3) were cultured in DMEM/Nutrient Glutamax supplemented with 10\% FBS 
and $1 \%$ Penicillin Streptomycin. Cells were maintained at $37^{\circ} \mathrm{C}$ in $5 \% \mathrm{CO}_{2}$. bEnd. 3 cells, passage between 25 and 35 , were seeded on the HA-am hydrogels (patterned or nonpatterned) at a density of 25,000 cells $/ \mathrm{cm}^{2}$ in supplemented media. Cell viability was assessed by Live/Dead staining assay on days 1 and 7 using a solution containing $1000 \mathrm{X}$ Calcein AM, 1000X Propidium Iodide and 1000X Hoechst in MEM medium (without phenol red and without FBS). Cells were incubated with the solution for $10 \mathrm{~min}$ and subsequently washed with MEM medium and imaged immediately after.

\subsection{Visualisation}

Images were acquired using either a laser confocal microscope (Leica SP8) equipped with a photon multiplier detector and a hybrid detector taking z-stacks using a $10 \mathrm{X}$ objective or with an inverted microscope (Olympus IX73) equipped with Orca-Flash 4.0 LT digital CMOS camera.

\section{Results}

\subsection{Simplified HA hydrogel preparation and patterning}

We demonstrate that the same chemical pathway, i.e., radical addition reaction, can be used for both cross-linking of HAam precursor solution and spatially controlled functionalization of the obtained hydrogel with the cell-adhesion RGD peptide in square areas with dimensions ranging from $100 \times$ $100 \mu^{2}$ down to $25 \times 25 \mu \mathrm{m}^{2}$, Fig. 3. Hydrogel areas of $200 \times 200 \mu \mathrm{m}^{2}$ could also be patterned with RGD peptide, Figs. 5 and 7 . Squares as small as $10 \times 10 \mu \mathrm{m}^{2}$ could be

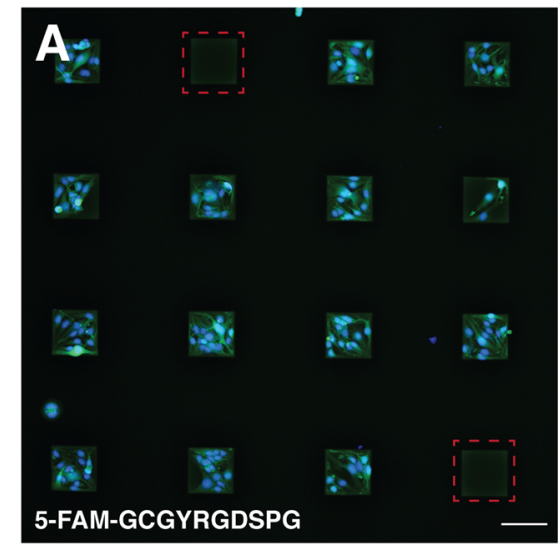

Fig. 3 Fluorescent images showing bEnd.3 cells growing selectively on square peptide patterns on the hydrogel surface on day 1 . A $100 \times$ $100 \mu^{2}$ 5FAM-GCGYRGDSPG patterns. Square green patterns of the RGD are visible, where cells did not adhere (marked in red dashed lines). Scale bar $100 \mu \mathrm{m}$. B $25 \times 25 \mu^{2}$ square GCGYRGDSPG functionalized with RGD peptide, Fig. 5, but for these areas no cell adhesion was observed. We conclude that crosslinking of HA-am derivative at a dose of $4.6 \mathrm{~J} / \mathrm{cm}^{2}$ was most suitable as it results in a hydrogel scaffold that was easy to handle and proved to be stable for long periods of time ( 30 days) under cell culture conditions. The optimal UV dose for patterning of the hydrogel was identified to be $1.9 \mathrm{~J} /$ $\mathrm{cm}^{2}$ since it showed high pattern fidelity in combination with selective cell adhesion to the patterned areas. Below follow details on the systematic characterisation of the hydrogel preparation and functionalization.

\subsection{Hydrogel formation and mechanical characterisation}

The minimum UV dose required to form a cross-linked hydrogel was determined to be $1.7 \mathrm{~J} / \mathrm{cm}^{2}$ resulting in a hydrogel with a Young's modulus $(E)$ of $0.53 \pm 0.16 \mathrm{kPa}$. Increasing the UV dose resulted in an increase in the $E$ of the hydrogel, as expected due to the higher degree of crosslinking, Fig. 4.

\subsection{Chemically patterned HA-am hydrogel samples}

Patterning of RGD peptides to HA-am hydrogels was confirmed by visualisation of a pattern formed by the fluorescently labelled peptide, Fig. 5. Here, the hydrogel was cross-linked at a constant UV dose of $4.6 \mathrm{~J} / \mathrm{cm}^{2}$ and the RGD peptides were linked using a UV dose of $1.9 \mathrm{~J} / \mathrm{cm}^{2}$. Good resolution was obtained for squares down to $10 \times 10 \mu \mathrm{m}^{2}$, whereas rounded corners were observed for the $5 \times 5 \mu \mathrm{m}^{2}$ squares.

It was observed that RGD peptides attached to the hydrogels with all UV exposure doses tested $\left(0.24-6.9 \mathrm{~J} / \mathrm{cm}^{2}\right)$.

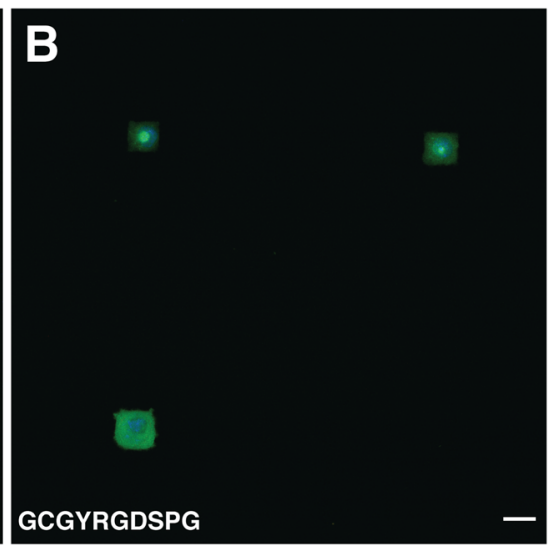

patterns. Substantially lower cell adhesion was observed on the smaller patterns. Scale bar $25 \mu \mathrm{m}$. Viable cells within the patterns are stained in green and dead cells (non-observed) are stained in red. Cell nuclei stained in blue (colour figure online) 
However, at the lower doses, a lower florescence intensity was observed, indicating that less RGD peptides were attached to the hydrogel. As the same pathway is used for both the cross-linking of the hydrogel and the RGD functionalization, it means that the extra UV dose to attach the RGD peptides will also increase the cross-linking density in the exposed areas. It is therefore important to identify the maximum UV exposure dosage that the hydrogel can receive before topographical changes were observed in the hydrogel, resulting from extreme cross-linking of the hydrogel precursor solution. Such indentations could affect the cell adhesion and proliferation and in our work, we observed these defects when the HA-am hydrogel was exposed to $6.9 \mathrm{~J} / \mathrm{cm}^{2}$, Fig. 6 . Hence, we decided to use an exposure dosage of $1.9 \mathrm{~J} / \mathrm{cm}^{2}$ for patterning the RGD peptides in this study to avoid any indentations in the gel.

\subsection{Cell adhesion on functionalized hydrogels}

To investigate if the RGD-peptide patterns supported cell adhesion and proliferation, brain endothelial cells (bEnd.3) were seeded on the selectively functionalized hydrogels. For this purpose, HA-am hydrogels were initially

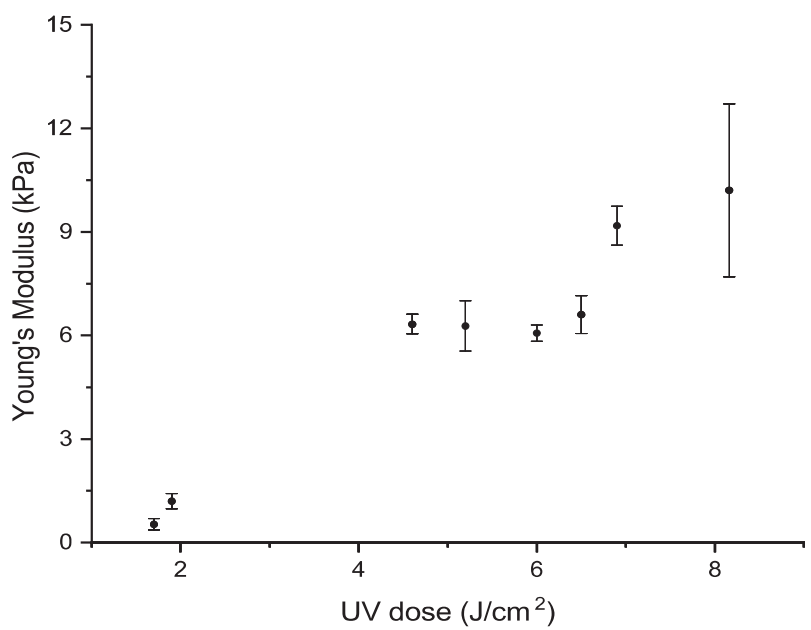

Fig. 4 Young's Modulus of the bulk hydrogel cross-linked at different UV doses. Error bars represent standard deviation from $n=3$

Fig. 5 Square micropatterns of 5FAM-GCGYRGDSPG-peptide on HA-am hydrogels could be achieved using different masks. A $200 \times 200 \mu \mathrm{m}^{2}, 200 \mu \mathrm{m}$ spacing. B $10 \times 10 \mu \mathrm{m}^{2}, 10 \mu \mathrm{m}$ spacing. C $5 \times 5 \mu \mathrm{m}^{2}, 15 \mu \mathrm{m}$ spacing. Scale bar $200 \mu \mathrm{m}$ in (A) and $10 \mu \mathrm{m}$ in $(\mathbf{B}, \mathbf{C})$ cross-linked at a constant UV dose of $4.6 \mathrm{~J} / \mathrm{cm}^{2}$, while the UV dose for RGD patterning was varied $\left(0.24-4.6 \mathrm{~J} / \mathrm{cm}^{2}\right)$. bEnd. 3 cells adhered to RGD patterns prepared using a UV dose of $1.9,2.3$ or $4.6 \mathrm{~J} / \mathrm{cm}^{2}$, but there was no cell adherence to samples prepared using a UV dose of 0.24 , 0.95 or $1.7 \mathrm{~J} / \mathrm{cm}^{2}$, Table 1 . When RGD peptides were patterned using $4.6 \mathrm{~J} / \mathrm{cm}^{2}$, cells were observed to adhere inbetween the patterns, due to over exposure, resulting in RGD adherence to the HA-am hydrogel outside the pattern areas.

As we used the same functional groups on the HA-am for forming the gel and attaching the RGD peptide via radical addition reaction, we also wanted to identify the maximum UV exposure dosage the HA scaffold could be subject to during cross-linking, while still having sufficient number of Am groups left to react with the RGD peptides to support cell adhesion. This was evaluated by varying the UV dose to cross-link the hydrogel $\left(4.0-10.6 \mathrm{~J} / \mathrm{cm}^{2}\right)$, while keeping the UV dose for the RGD patterning constant $\left(1.9 \mathrm{~J} / \mathrm{cm}^{2}\right)$. In our system using HA-am with $14 \%$ functionalization, the maximum UV exposure dose to form the gel and still allow for RGD patterning and cell adhesion was found to be $8.16 \mathrm{~J} / \mathrm{cm}^{2}$, Table 2. At UV dosages from $10.6 \mathrm{~J} / \mathrm{cm}^{2}$ and above, cells would not adhere to the patterns. This indicates that there were not enough Am groups available to attach

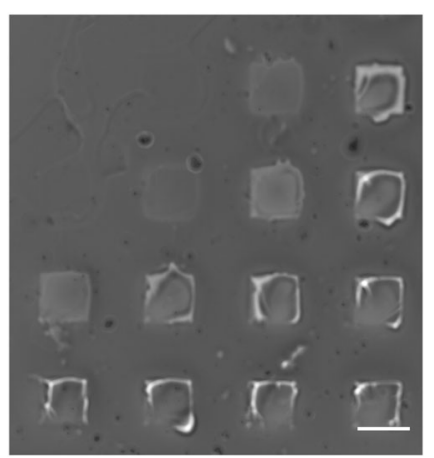

Fig. 6 Bright field image of HA-am hydrogel exposed with a dose of $6.9 \mathrm{~J} / \mathrm{cm}^{2}$ through a photomask with $200 \times 200 \mu \mathrm{m}^{2}$ openings. Topographical effects are observed in the areas exposed to the UV light. Scale bar $200 \mu \mathrm{m}$
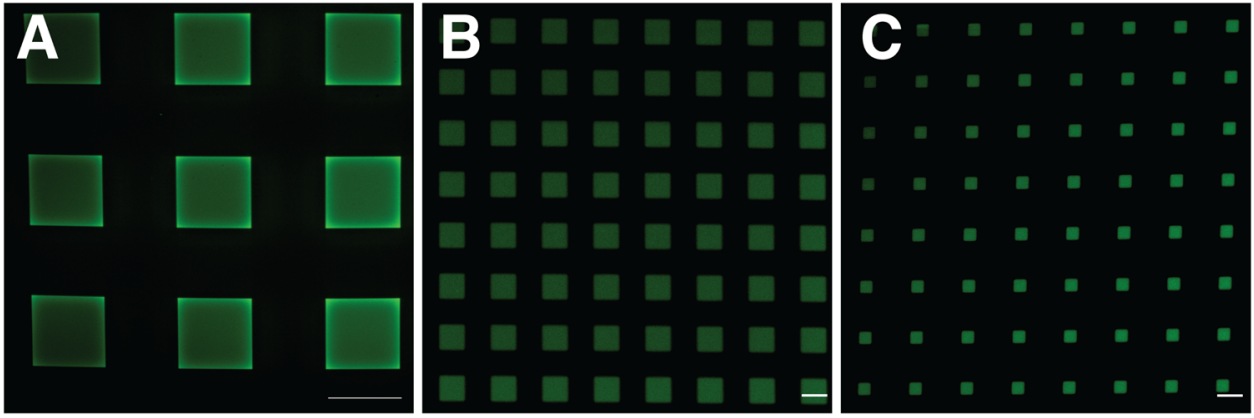
Table 1 The cell response varied for different UV dosages tested for the RGD functionalization. The HA-am hydrogels were formed using a constant UV dose of $4.6 \mathrm{~J} / \mathrm{cm}^{2}$

\begin{tabular}{lll}
\hline $\begin{array}{l}\text { UV dose for RGD } \\
\text { functionalization }\left(\mathrm{J} / \mathrm{cm}^{2}\right)\end{array}$ & $\begin{array}{l}\text { Young's } \\
\text { modulus }(\mathrm{kPa})\end{array}$ & Cell response \\
\hline 0.24 & & $\begin{array}{l}\text { No cell adhesion } \\
\text { No cell adhesion }\end{array}$ \\
0.96 & $0.53 \pm 0.16$ & No cell adhesion \\
1.7 & $1.12 \pm 0.22$ & Cell adhesion \\
1.9 & $6.32 \pm 0.28$ & $\begin{array}{l}\text { Cell adhesion, cells } \\
\text { crossing between } \\
\text { the patterns }\end{array}$ \\
\hline
\end{tabular}

Table 2 When using different UV dosages to form the hydrogel, the cell response varied. The HA-am hydrogels were funcitonalized with RGD using a constant UV dose of $1.9 \mathrm{~J} / \mathrm{cm}^{2}$

\begin{tabular}{lll}
\hline $\begin{array}{l}\text { UV dose to form the } \\
\text { hydrogel }\left(\mathrm{J} / \mathrm{cm}^{2}\right)\end{array}$ & Young's modulus $(\mathrm{kPa})$ & Cell response \\
\hline 4.0 & & Cell adhesion \\
4.6 & $6.32 \pm 0.28$ & Cell adhesion \\
6.9 & $9.18 \pm 0.57$ & Cell adhesion \\
8.2 & $10.20 \pm 2.50$ & Cell adhesion \\
10.6 & & No cell \\
& & adhesion \\
\hline
\end{tabular}

sufficient RGD peptides to permit cell adhesion to the hydrogels.

\subsection{Role of peptide sequence on cell adhesion}

To investigate the role of the RGD peptide related to the cell adhesion on the HA hydrogel, we prepared hydrogel samples initially cross-linked at $4.6 \mathrm{~J} / \mathrm{cm}^{2}$ and used the four different peptide sequences to form patterns with a constant UV dose of $1.9 \mathrm{~J} / \mathrm{cm}^{2}$. The results are summarised in Table 3.

For the shorter peptide sequence, it was observed that the bEnd.3 cells did not adhere to the non-fluorescent CRGDS patterns, whereas the cells did adhere to the fluorescently labelled 5FAM-CRGDS patterns. However, the cells showed a rounded morphology and did not spread on the pattern, even after 7 days in culture, Fig. 7. This indicates that 5FAM-RGDSC peptide supported cell viability but that they do not provide the optimal substrate for endothelial cell adhesion. For the longer peptides, bEnd.3 cells adhered to both the fluorescently labelled RGD-peptide sequences, 5FAM-GCGYRGDSPG, and the non-labelled sequence, GCGYRGDSPG, and showed a healthy phenotype [33] with an elongated morphology characteristic of endothelial cells on both patterns, Fig. 7.
Table 3 Cell adhesion and proliferation on different RGD-peptide sequences

\begin{tabular}{lll}
\hline Peptide sequence & Fluorescent & Cell adhesion \\
\hline RGDSC & No & No \\
5FAM-RGDSC & Yes & Yes \\
GCGYRGDSPG & No & Yes \\
5FAM-GCGYRGDSPG & Yes & Yes \\
\hline
\end{tabular}

\section{Discussion}

In this work, we present a straightforward and simplified approach to fabricate $200 \mu \mathrm{m}$ thick HA hydrogels, where the cell adhesion of brain endothelial cells can be controlled on the micrometre scale. The fabrication of these hydrogelbased cell culture substrates relies on two sequential and short UV exposure steps. An advantage of this simplified method, using UV for both the formation of the hydrogel and the patterning, is that the stiffness of the hydrogel can be fine-tuned independently from the polymer degree of functionalization, which is not the case when, e.g., Michaeltype addition reactions are used. In such reaction schemes, the hydrogel will cross-link until all functional groups (or all cross-linker) are consumed and the stiffness of the resulting hydrogel is thus determined at the start of the process, by the degree of functionalization of the precursor material or the initial cross-linker concentration. Our approach permits fine-tuning of the stiffness of the resulting hydrogel after precursor synthesis and tailoring for the desired application during the fabrication of the scaffold. In our system, we can adjust the stiffness of the material by carefully choosing the appropriate hydrogel cross-linking UV dose and the patterning dose to obtain the desired stiffness that the cells will experience. This behaviour has also been shown in similar systems where HA methacrylate was exposed to varying UV exposure times (0-90 s) generating a mechanical gradient throughout the hydrogel from $\sim 3$ to $100 \mathrm{kPa}$ [12]. In this work, where the adhesion of brain microvasculature cells were studied, we identified a UV dose of $4.6 \mathrm{~J} / \mathrm{cm}^{2}$ for forming the gel followed by $1.9 \mathrm{~J} / \mathrm{cm}^{2} \mathrm{UV}$ exposure for the patterning RGD peptides, as the best settings. This resulted in an initial hydrogel stiffness of $6.3 \pm 0.3 \mathrm{kPa}$, which was then increased to $6.6 \pm$ $0.6 \mathrm{kPa}$ after the RGD patterning. The resulting gel showed optimal properties as it permitted easy handling and stability over a relevant time span for cell culture. Lower exposure dose for peptide patterning resulted in impaired cell adhesion as a result of too low peptide binding concentration. A higher exposure dose, on the other hand, resulted in overexposed gels as seen by cells adhering outside the specified patterns. Moreover, we could achieve high-fidelity patterns down to $10 \times 10 \mu \mathrm{m}^{2}$. In standard UV lithography where 


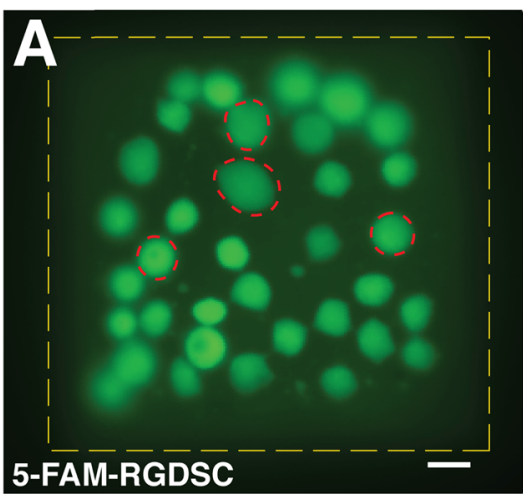

Fig. 7 bEnd. 3 morphology on different peptide sequences. A Fluorescent image (day 7) showing bEnd.3 cells growing selectively on the peptide functionalized area $\left(200 \times 200 \mu \mathrm{m}^{2}\right)$, marked with a yellow dashed line. The cells remain alive but do not elongate (marked with

patterns are transferred onto a solid substrate, one can usually obtain high-resolution patterns down to $1 \times 1 \mu \mathrm{m}^{2}$ but due to the soft nature of the hydrogel, we could not perform the exposure under hard contact conditions, thus reducing the resolution. A pattern resolution of $10 \times 10 \mu \mathrm{m}^{2}$ will permit future modelling of the brain microvasculature, as brain capillaries are 7-10 $\mu \mathrm{m}$ in diameter [34].

In addition, we explored if different RGD sequences would affect the adhesion and spreading of the brain endothelial cells in our scaffold as it has been shown that the structural conformation of the RGD-peptide sequence affects cell-adhesion affinity [35]. Moreover, it has been reported that cell adhesion to RGD peptides on different surfaces depends on the distance between the peptide and the surface, where longer RGD peptides have shown improved cell-adhesion properties [36-39]. This might be an explanation to why we only observe cell adherence on the longer peptide but not on the patterns formed by the shorter RGD peptides. Interestingly, cells did not adhere to the shorter non-fluorescent RGD peptide, but could still adhere and remain viable on the shorter fluorescent counterpart, while failing to elongate and instead displaying a rounded morphology. This is probably due to an inability to establish specific interactions between the integrin receptors on the cell surface and the RGD peptide. We believe that this platform could have a major applicability in the tissue engineering field, for the development of organs-on-chip models as well as in high throughput applications in the future.

\section{Conclusion}

In the present study we demonstrated a simplified method where HA-am derivative can participate in sequential photo-initiated radical addition reactions to form hydrogel

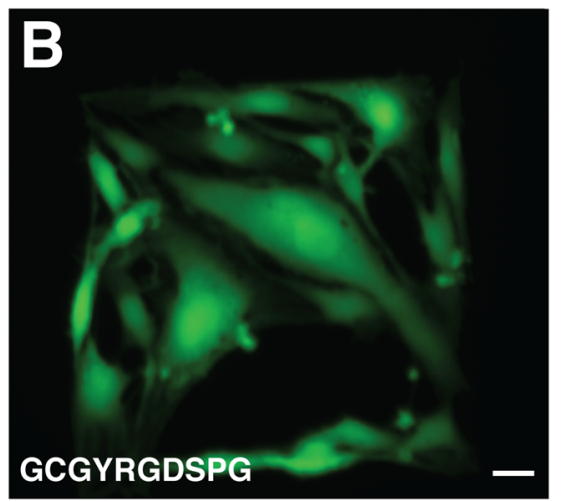

red dashed line). B bEnd. 3 cells show an elongated morphology on the pattern $\left(200 \times 200 \mu \mathrm{m}^{2}\right)$ formed by the longer peptide sequence already at day 1 . Scale bar is $20 \mu \mathrm{m}$ (colour figure online)

films with spatially defined cell adhesive peptides. The functionalization of HA hydrogel with RGD peptides was possible due to UV light-triggered radical thiol-ene addition of the thiol group of the peptide to the Am groups that remained unreacted after the photo-cross-linking step. Using UV lithography, we were able to generate the RGD patterns in spatially defined areas of the hydrogel film, as small as $10 \times 10 \mu \mathrm{m}^{2}$. In addition, we showed that bEnd.3 cells selectively adhere to and proliferate on the longer GCGYRGDSPG-peptide patterns whereas the shorter CRGDS-peptide patterns only support adhesion. This demonstrates that HA-am derivative is a promising material for fabrication of in vitro models with in situ HA hydrogel formation.

Acknowledgements This project has received funding from the European Research Council (ERC) under the European Union's Horizon 2020 research and innovation programme (grant agreement No 757444). The research has also been financed by Knut and Alice Wallenberg Foundation (grant number WAF 2016.0112) and the Swedish Research Council Formas (grant number 216-2014-1247). The National Council of Science and Technology of Mexico funded part of the doctoral studies of AMPH. MA is supported by Novo Nordisk Foundation (Grant No. NNF16OC0020792), and by Marie Curie fellowship programme (Grant No. 746270/H2020-MSCAIF-2016). The Novo Nordisk Foundation Center for Stem Cell Biology is supported by Novo Nordisk Foundation (Grant No. NNF17CC0027852). We thank Prof. Jöns Hilborn and Dr. Ayan Samanta, both Uppsala University, for providing access to some of the experimental equipment necessary in this work (rheometer, freeze dryer and nuclear magnetic resonance spectrometer). Open access funding provided by Uppsala University.

\section{Compliance with ethical standards}

Conflict of interest The authors declare that they have no conflict of interest.

Publisher's note Springer Nature remains neutral with regard to jurisdictional claims in published maps and institutional affiliations. 
Open Access This article is licensed under a Creative Commons Attribution 4.0 International License, which permits use, sharing, adaptation, distribution and reproduction in any medium or format, as long as you give appropriate credit to the original author(s) and the source, provide a link to the Creative Commons license, and indicate if changes were made. The images or other third party material in this article are included in the article's Creative Commons license, unless indicated otherwise in a credit line to the material. If material is not included in the article's Creative Commons license and your intended use is not permitted by statutory regulation or exceeds the permitted use, you will need to obtain permission directly from the copyright holder. To view a copy of this license, visit http://creativecommons. org/licenses/by/4.0/.

\section{References}

1. Thiele J, Ma Y, Bruekers SMC, Ma S, Huck WTS. 25th anniversary article: designer hydrogels for cell cultures: a materials selection guide. Adv Mater. 2014;26:125-48. https://doi.org/10. 1002/adma.201302958.

2. Verhulsel M, Vignes M, Descroix S, Malaquin L, Vignjevic DA, Viovy JL. A review of microfabrication and hydrogel engineering for micro-organs on chips. Biomaterials. 2014;35:1816-32. https://doi.org/10.1016/j.biomaterials.2013.11.021.

3. Moon JJ, Hahn MS, Kim I, Nsiah BA, West JL. Micropatterning of poly(ethylene glycol) diacrylate hydrogels with biomolecules to regulate and guide endothelial morphogenesis. Tissue Eng A. 2009;15:579-85. https://doi.org/10.1089/ten.tea.2008.0196.

4. Hahn MS, Taite LJ, Moon JJ, Rowland MC, Ruffino KA, West JL. Photolithographic patterning of polyethylene glycol hydrogels. Biomaterials. 2006;27:2519-24. https://doi.org/10.1016/j.bioma terials.2005.11.045.

5. Beckwith KM, Sikorski P. Patterned cell arrays and patterned cocultures on polydopamine-modified poly(vinyl alcohol) hydrogels. Biofabrication. 2013;5:45009-22. https://doi.org/10.1088/ 1758-5082/5/4/045009.

6. Hynd MR, Frampton JP, Burnham M-RR, Martin ML, DowellMesfin NM, Turner JN. et al. Functionalized hydrogel surfaces for the patterning of multiple biomolecules. J Biomed Mater Res A. 2006;81:347-54. https://doi.org/10.1002/jbm.a.31002.

7. Lutolf MP, Hubbell JA. Synthetic biomaterials as instructive extracellular microenvironments for morphogenesis in tissue engineering. Nat Biotechnol. 2005;23:47-55.

8. Drury JL, Mooney DJ. Hydrogels for tissue engineering: scaffold design variables and applications. Biomaterials. 2003;24:4337-51.

9. Bignami A, Hosley M, Dahl D. Hyaluronic acid and hyaluronic acid-binding proteins in brain extracellular matrix. Anat Embryol. 1993;188:419-33.

10. Kim IL, Khetan S, Baker BM, Chen CS, Burdick JA. Fibrous hyaluronic acid hydrogels that direct MSC chondrogenesis through mechanical and adhesive cues. Biomaterials. 2013;34:5571-80. https://doi.org/10.1016/j.biomaterials.2013.04.004.

11. Ananthanarayanan B, Kim Y, Kumar S. Elucidating the mechanobiology of malignant brain tumors using a brain matrix-mimetic hyaluronic acid hydrogel platform. Biomaterials. 2011;32:7913-23. https://doi.org/10.1016/j.biomaterials. 2011.07.005.

12. Marklein RA, Burdick JA. Spatially controlled hydrogel mechanics to modulate stem cell interactions. Soft Matter. 2009;6:136-43. https://doi.org/10.1039/b916933d.

13. Lei Y, Gojgini S, Lam J, Segura T. The spreading, migration and proliferation of mouse mesenchymal stem cells cultured inside hyaluronic acid hydrogels. Biomaterials. 2010;32:39-47. https:// doi.org/10.1016/j.biomaterials.2010.08.103.
14. Khetan S, Burdick JA. Patterning network structure to spatially control cellular remodeling and stem cell fate within 3dimensional hydrogels. Biomaterials. 2010;31:8228-34. https:// doi.org/10.1016/j.biomaterials.2010.07.035.

15. Hanjaya-Putra D, Wong KT, Hirotsu K, Khetan S, Burdick JA, Gerecht S. Spatial control of cell-mediated degradation to regulate vasculogenesis and angiogenesis in hyaluronan hydrogels. Biomaterials. 2012;33:6123-31. https://doi.org/10.1016/j.biomateria 1s.2012.05.027.

16. Shi L, Carstensen H, Hölzl K, Lunzer M, Hilborn J, Ovsianikon A. et al. Dynamic coordination chemistry enables free directional printing of biopolymer hydrogel. Chem Mater. 2017;29:5816-23. https://doi.org/10.1021/acs.chemmater.7b00128.

17. Gramlich WM, Kim IL, Burdick JA. Synthesis and orthogonal photopatterning of hyaluronic acid hydrogels with thiolnorbornene chemistry. Biomaterials. 2013;34:9803-11. https:// doi.org/10.1016/j.biomaterials.2013.08.089.

18. Wade RJ, Bassin EJ, Gramlich WM, Burdick JA. Nanofibrous hydrogels with spatially patterned biochemical signals to control cell behavior. Adv Mater. 2015;27:1356-62. https://doi.org/10. 1002/adma.201404993.

19. Jing J, Fournier A, Szarpak-Jankowska A, Block MR, Auzély-Velty R. Type, density, and presentation of grafted adhesion peptides on polysaccharide-based hydrogels control preosteoblast behavior and differentiation. Biomacromolecules. 2015;16:715-22. https://doi. org $/ 10.1021 / \mathrm{bm} 501613 \mathrm{u}$.

20. Griffin DR, Borrajo J, Soon A, Acosta-Vélez GF, Oshita V, darling N. et al. Hybrid photopatterned enzymatic reaction (HyPER) for in situ cell manipulation. ChemBioChem. 2014;15:233-42. https://doi.org/10.1002/cbic.201300687.

21. Goubko CA, Majumdar S, Basak A, Cao X. Hydrogel cell patterning incorporating photocaged \{RGDS $\}$ peptides. Biomed Microdevices. 2010;12:555-68. https://doi.org/10.1007/s10544010-9412-7.

22. Kharkar PM, Kiick KL, Kloxin AM. Designing degradable hydrogels for orthogonal control of cell microenvironments. Chem Soc Rev. 2013;42:7335-72. https://doi.org/10.1039/C3CS60040H.

23. Ma Y, Yung LYL. Detection of dissolved $\mathrm{CO}_{2}$ based on the aggregation of gold nanoparticles. Anal Chem. 2014;86:2429-35. https://doi.org/10.1021/ac403256s.

24. Shi L, Wang F, Zhu W, Xu Z, Fuchs S, Hilborn J, et al. Selfhealing silk fibroin-based hydrogel for bone regeneration: dynamic metal-ligand self-assembly approach. Adv Funct Mater. 2017;27. https://doi.org/10.1002/adfm.201700591.

25. Liu VA, Bhatia SN. Three-dimensional photopatterning of hydrogels containing living cells. Biomedical Microdevices. 2002;4:257-266. https://doi.org/10.1023/A:1020932105236.

26. Vanderhooft JL, Alcoutlabi M, Magda JJ, Prestwich GD. Rheological properties of cross-linked hyaluronan-gelatin hydrogels for tissue engineering. Macromol Biosci. 2009;9:20-8. https://doi. org/10.1002/mabi.200800141.

27. Park YD, Tirelli N, Hubbell JA. Photopolymerized hyaluronic acidbased hydrogels and interpenetrating networks. Biomaterials. 2002;24:203-10. https://doi.org/10.1016/B978-008045154-1.50023-X.

28. Lam J, Truong NF, Segura T. Design of cell-matrix interactions in hyaluronic acid hydrogel scaffolds. Acta Biomater. 2014;10:1571-80. https://doi.org/10.1016/j.actbio.2013.07.025.

29. Polizzotti BD, Fairbanks BD, Anseth KS. Three-dimensional biochemical patterning of click-based composite hydrogels via thiolene photopolymerization. Biomacromolecules. 2008;9:1084-7. https:// doi.org/10.1021/bm7012636.

30. Pedron S, Pritchard AM, Vincil GA, Andrade B, Zimmerman SC, Harley BAC. Patterning three-dimensional hydrogel microenvironments using hyperbranched polyglycerols for independent control of mesh size and stiffness. Biomacromolecules. 2017;18:1393-400. https://doi.org/10.1021/acs.biomac.7b00118. 
31. De Luca AC, Stevens JS, Schroeder SLM, Gbuilbaud J-B, Saiani A, Downes S. et al. Immobilization of cell-binding peptides on poly-e-caprolactone film surface to biomimic the peripheral nervous system. J Biomed Mater Res A. 2012;101A:491-501. https:// doi.org/10.1002/jbm.a.34345.

32. Gandavarapu NR, Azagarsamy MA, Anseth KS. Photo-click living strategy for controlled, reversible exchange of biochemical ligands. Adv Mater. 2014;26:2521-6. https://doi.org/10.1002/adma.201304847.

33. Anderson DEJ, Hinds MT. Endothelial cell micropatterning: methods, effects, and applications. Ann Biomed Eng. 2011;39:2329-45. https://doi.org/10.1007/s10439-011-0352-z.

34. Wong AD, Ye M, Levy AF, Rothstein JD, Bergles DE, Searson PC. The blood-brain barrier: an engineering perspective. Front Neuroeng. 2013;6. https://doi.org/10.3389/fneng.2013.00007.

35. Bellis SL. Advantages of RGD peptides for directing cell association with biomaterials. Biomaterials. 2011;32:4205-10. https:// doi.org/10.1016/J.BIOMATERIALS.2011.02.029.
36. Beer JH, Springer KT, Coller BS. Immobilized Arg-Gly-Asp (RGD) peptides of varying lengths as structural probes of the platelet glycoprotein IIb/IIIa receptor. Blood. 1992;79:117-28. https://doi.org/10.1182/blood.v79.1.117.bloodjournal791117.

37. Craig WS, Cheng S, Mullen DG, Blevitt J, Pierschbacher MD. Concept and progress in the development of RGD-containing peptide pharmaceuticals. Biopolymers. 1995;37:157-75. https:// doi.org/10.1002/bip.360370209.

38. Kantlehner M, Finsinger D, Meyer J, Schaffner P, Jonczyk A. et al. Selective RGD-mediated adhesion of osteoblasts at surfaces of implants. Angew Chem. 1999;38:560-2. https://doi.org/10. 1002/(SICI)1521-3773(19990215)38:4<560::AID-ANIE560>3.0. $\mathrm{CO} ; 2-\mathrm{F}$.

39. Auernheimer J, Dahmen C, Hersel U, Bausch A, Kessler H. Photoswitched cell adhesion on surfaces with RGD peptides. J Am Chem Soc. 2005;127:16107. https://doi.org/10.1021/ja 053648q. 